\title{
EUROPEAN UNION - REFORMS - HUNGARIAN INTERESTS. WHAT KIND OF EUROPEAN UNION WOULD WE LIKE?
}

\author{
TIBOR PALÁNKAI \\ Professor Emeritus, member of the Hungarian Academy of Sciences, \\ Department of World Economy, Corvinus University of Budapest, Fövám tér 8, \\ H-1092 Budapest, Hungary.E-mail: tibor.palankai@uni-corvinus.hu
}

\begin{abstract}
The lecture deals with broad topics. First, it addresses some questions related to the current state of the EU integration regarding institutions and common policies. Second, it discusses the continued importance, the main results and hindering factors related to the Lisbon Programme, with a special emphasis on the educational system in Europe and Hungary. Third, the lecture deals with some possibilities in changing the EU's rather limited external relation models to more flexible instruments.
\end{abstract}

Keywords: Hungary, reforms, EU

Journal of Economic Literature (JEL) code: ?????????

\section{INTRODUCTION}

Although the subtitle of lecture may sound journalistic, I feel this is the way to express the objective of it properly, while not making any concessions regarding the analysis.

I examine three major issues in this lecture:

- The state of the EU integration (institutions and policies)

- The Lisbon Programme

- Possible external relation models

I also touch on the major aspects of EU reforms in various fields for some short remarks, such as the CAP, the common budget, and the Euro. 


\section{ABOUT THE STATE OF EU INTEGRATION}

In my opinion, a democratic and decentralized federative development of the EU is what corresponds most to the interests of Hungary. Our interest is the consolidation and the efficient operation of the EU and its institutions. The Lisbon Treaty is a leap forward in this direction and it would be desirable for it to come into force.

The development of the EU entered into a new stage in the last decade. The intensity of economic relations as well as the interdependency of member states reached a high level. The EU is unique in the world with its single market, currency and the supranational elements of its institutional system (unique among some 200 different integration alignments), and it is more and more regarded as certain form of a state. As theoretic literature denotes, the sum of all common policies are creating a unique image of statehood. In other words, policies are turning into polity. This is a qualitative turn and a qualitatively new period in the development of the Union.

This is also manifested in the constitutional process. The recognition of the independent "legal personality", the consolidation of the institutions of the Union as well as the increase of their efficiency all result from the processes mentioned above. On the other hand, it was not without a reason that the constitutional process got stuck in recent years, as it carried several contradictions.

a) Although the debates dealt with the future of the EU, the compromises rather reflected a closure of the past. Not only the future directions of the development of the EU remained ambiguous, but the discussions also failed to determine the present as well. It is widely agreed that the development process of the EU is currently in a special transitional situation; it is by now far more than an international organization, but less, and in many respects much less than a traditional federation. Opinions are divided about what it really is, and I present only a list of definitions here, which appropriately reflect the theoretical confusion on the issue. ${ }^{1}$ It is no wonder that the literature fails to describe the future. But what is more important is that the minimal political consensus regarding the future direction of the development of the Union has not been agreed upon by the member states.

b) The political background of the constitutional process was missing. In history, the birth of constitutions has usually been connected to great historical turning-points (for example revolutions or wars of independence) and they had been supported by mass movements. Although mending democracy deficits of the EU was an objective, the initiators of the changes were once again the elites, who were not backed by mass movements. 
c) The constitutional process coincided with the expansion crisis of the Union, which was not only the result of the fact that the number of member states nearly doubled (increased from 15 to 27), but also because both the 2004 and 2007 accession countries were much less mature for integration. Most new members were not duly prepared for the integration (competitiveness and the development level of institutions), while absorption and integration capacities of the earlier members were unsatisfactory as well. The crisis had structural, financial as well as political and institutional aspects. The economies of the earlier members were structurally not prepared for the competition of the new ones (dislocation), and both the EU and the national budgets lacked the funds to finance the expansion. High unemployment rates did not make the immediate opening of labour markets possible, which generated political tensions on both sides. From an institutional point of view, the constitution offered a solution for the expansion, but only ex post.

Hungary has interests in the development of an efficient decision-making system in the Union, in the further expansion of the authorities and the legislative role of the European Parliament as well as in maintaining and strengthening the role of the Commission. The Commission is the most important policy-making institution of the Union, while final decision making is shared by the Council and the Parliament. Being a policy-maker and an executive institution, the weakening of its role does not match our interests. In my opinion, the decrease in the number of the commissioners is not an agreeable development in this respect. High headcount might make functioning and decision-making more difficult, but much depends on the proper operation of the organization, which can solve these problems. The Commission with 27 members has proven to be operable. On the other hand, the number of portfolios grows parallel with the number of commissioners, which reappraises numerous fields. If a commissioner is responsible for several issues, he or she will select which he or she can succeed in. If results must be produced on a narrower field, important decisions could be made in issues that otherwise would be ignored. This question is also a good example for the extent discussions are needed in order to clarify at least the viewpoints and the interests.

With regard to intergovernmentalism and/or federalism, we have an interest in a democratic development that duly considers the interests of smaller countries and brings integration closer to citizens. The current "intergovernmental" mechanisms are favour national bargains behind the scenes, while a federative evolution could guarantee our appropriate participation in decision-making.

The internal market is a special mixture of liberalized and regulated markets on the level of the Union. Interestingly enough, both aspects are subject to bitter debates. Full liberalization meets stout resistance in some public sectors (energy 
providers, transportation or telecommunication), and several member states try to postpone certain measures, moreover to protect the interests of their "national economies". Hungary has not stayed away from this completely.

On the other hand, the operation of the market is regulated by thousands of mostly Commission directives or decisions. As the single internal market is becoming a reality, the structures of market regulation are spreading on the Union level as well. The regulation endeavours to meet the requirements of normal market operations and daily demands. These rules are complex; they refer to product quality, protection of consumers and the environment or just try to enforce social requirements. The regulation comprehends production, trade, and the financial sectors as well; however it is the least efficient in the latter.

Due to its giant bureaucracy, the Commission in Brussels is the favourite target of the daily press. The "straight cucumber" is the beloved topic, which we can meet every day in the Hungarian media as well, together with the usual intellectual reluctance. However, most of the rules and regulations are not born in office buildings. These rules are mostly forced by lobbies and interests; the Commission tries to react to their pressure. It is another matter that at the same time every measure interferes with the interests of others and these are often louder than the justifying arguments. The latter cannot bring sensations, but complaining presumably increases the number of readers. "Straight cucumber" is about the protection of the producers' interest. Bad quality products should not enter the market. In a wider context, we made great steps towards "Europe" by complying with the rules and the hygienic restrictions. It is another matter that in this particular case it is not forbidden to produce curved cucumbers. They can be grown, brought to the market, and if there is a demand for them, sold. The control is more rigorous - and it is fortunately the case - when the product might endanger the environment or health.

\section{THE LISBON PROGRAMME AND THE INTERESTS OF HUNGARY}

\subsection{About the evaluation of the Lisbon Programme}

The issue of competitiveness has been the focus of EU policies since the 1980's. It became obvious that EU is loosing ground on global markets, especially in high technologies and the service sector. The answer was partly the total integration of the markets, which was aimed to be achieved by creating the single internal market. From the economic policy viewpoint, the provision of the Single European Act was also significant, which included research and development policies in the common policies. The Framework Programmes were launched and both the 
Maastricht and the Amsterdam Treaties underpinned that the competitiveness of the industry needed appropriate "actions". We are convinced that the Lisbon decisions in April 2000 can be regarded as a turning-point. These aimed to turn the EU into the most competitive economy on global markets by 2010 by executing the so called e-Europe programme. The Lisbon Programme is a strategic and relevant answer to the challenges of "global transformation" (Balcerowicz, Giddens, etc.).

The Lisbon Programme is considered to be important in terms of the modernization and the as well as competitiveness of the Union and the member states. Our vital long-term development interests are connected to it. The Lisbon Programme was accepted in April 2000 and it defined several different and, in many respects, controversial objectives:

- Creating an economy that is competitive on the global markets.

- Distribution and application of ICT in every fields of life.

- Creating a knowledge-based society.

- Dynamic economic growth (improving macroeconomic indicators).

- Sustainability of economic growth (environment).

- Creating the European model of social integration (full employment and social welfare).

The list shows a certain structural order. Of course there is no chance for global competitiveness without ICTs and the creation of the knowledge-based society. Only these can make dynamic economic growth as well as good macroeconomic performance a reality. The sustainability of the environment cannot be examined in itself, it requires competitiveness. Competitiveness depends on social security, but only a competitive economy is able to produce the funds required for high quality social care. Priorities might be inverted on a political basis, but not at the expense of internal consistencies. Any social distribution without the proper funds will have grave consequences. The inner consistence of the Lisbon Programme is widely debated, especially in terms of competitiveness and the environmental and social sensitivity.

The importance of the Lisbon Agenda is that the EU attempts to prepare a long-term strategic modernization programme, which outlines tasks in a complex way, but also setting priorities. The programme is a socio-economic vision that endeavours to restore Europe's leading role and ensure its competitiveness in a globalizing world. It is regarded many as a kind of European social and economic development model, which represents the European Union's adaptation of the traditional concept of the European eco-social market economy.

The Lisbon Programme is widely debated; scepticism is general, especially regarding its relevance and feasibility. We do not agree with them, but on the other 
hand, the refinement of the evaluation of the situation, the specification of the objectives, as well as providing the means for implementation are all required. The example of the Scandinavian countries demonstrates that contrary to the wide-spread sceptical opinions, good economic performance and competitiveness are not inconsistent with social consciousness and social policies. "Sweden and Finland have combined high growth and low unemployment with the welfare state that is regarded as the embodiment of the European ideal.".2

The mid-term evaluation of the programme took place in 2005 (Sapier, Wim Kok, European Council). Deficiencies can be summarized as follows:

- the governments did not find the program relevant;

- the lack of real action programmes;

- the definitive financing of the programme is unsolved;

- its relation to "structural reforms" is not clarified;

- the programme for internal convergence is missing;

- its academic level analysis did not happen;

- it was not publicized to the society.

Some modifications took place following 2005 (Lisbon II.). As a result of the revisions, the preparation and the continuous control of national action plans began, based on the decisions of the Commission and the Council. Hungary prepared and handed in its action plan in October 2005, in due time, and the Lisbon Programme was taken into due consideration when preparing the Second National Development Plan. The EU determined the priorities of the programme for the next 3 years (jobs and growth) and the objective of becoming the "most competitive economy of the world" is no longer bound to the deadline of 2010. It is a fact that similar proposals to date have all failed because they were not backed by Community funds. Thus, including the chapter of subsidies for competitiveness in the financial perspective for 2007-2013 is particularly welcome, even if the budgeted funds are somewhat modest.

On the other hand, it is slowly being realized that achieving the Lisbon objectives is to a certain degree subject to convergence within Europe, in other words, Southern and Central-Eastern Europe must catch up to Northern and Western Europe. Europe's convergence with its global competitors is also subject to the internal balancing. The Lisbon process had been monopolized by the developed EU countries since the beginning and it was only extended to the accession countries later and with a moderate conviction. Any kind of confrontation of "competitiveness" and "cohesion" in the budget is not acceptable. It would be essential for the EU to acknowledge the importance of the catching up for the new member states in the improvement of its global competitiveness and position. The findings of the 
Wim Kok report are favourable and so are the efforts to take "Lisbon" much more into account in the new budget. On the other hand, provisions suggest that significant funds could be retained for the most developed countries on the pretext of "competitiveness" in contradiction to "cohesion". Thus, we must support the effort, especially regarding the delay of the programme, but we must act firmly that we are also entitled to those subsidies for "competitiveness" in the same way and extent. This way, the possibility of our access to more funds under more titles can be improved. We also agree with the opinions that cohesion in itself improves competitiveness.

\subsection{The Lisbon Programme and structural reforms}

In respect of the success of the Lisbon Programme, it is essential to recognize that global transformation would require fundamental and radical structural reforms in every field of the society and the economy. The basic directions of the modernization and reform necessities can be derived from the substantive and structural changes of this global transformation. These reforms have substantive, organizational-institutional (ownership), public managerial as well as financial aspects. The reforms are pressing primarily in the institutional and governance dimensions both on the global and the EU levels, as well as in the case of national structures.

- The continuous modernization of the structure and technology of production. This is the job of the enterprises as the pressure of global competition makes it unavoidable. The state should only provide an encouraging economic policy (governance) framework by supporting research and development, appropriate competition policies and suitable circumstances on financial markets.

- A comprehensive and radical substantive and methodological reform of education is a prerequisite for the knowledge-based society, although the funding requirements of this issue are quite significant.

- Governance faces qualitatively new demands due to global integration. It means much more than the necessity of the reform of public administration; reforms are required in several fields of the society and the economic policy.

- The standard and the efficiency of public management is a key factor of competitiveness. It affects all fields, but it culminates in the reform of public finances. The reform of health care is the matter of public management and funding, especially in the short run. However, almost all fields (education, public administration, etc.) need fundamental changes in this respect. Improving the quality of public services as well as increasing their efficiency is a significant issue. 
- The demographic crisis peculiar to developed countries should also be mentioned in connection with the reforms, which calls for new population policies, and makes the reform of pension schemes especially urgent.

- The wide-ranging reform of social systems in inevitable if the reforms and the improvement of public management are to be successful.

The preliminary assumption of the reforms is that regulation must be harmonized with the requirements of a globally competitive market economy. Nowadays we often talk about a "socially" controlled market (local authorities, NGO's, civil organizations, trade unions besides the "state"), and the reforms require not only liberalization but an efficient structure of institutions and policies as well. Regulation is often neither market-conform (welfare policy mixes up with market) nor 'global-conform' (leaves global determinations out of consideration).

National reforms are typically connected to so called structural problems. Debates on the necessity of these so called structural reforms are widespread in several countries. These reforms are mostly demanded in the fields of market operation and institutional and regulatory deficiencies. Critics cite inflexible capital and labor market regulations, high factor prices such as labor costs as well as the long awaited reforms of public services (health care, education and public administration) as structural problems. One of the main reasons behind poor economic performance is excessive central redistribution, especially the overspending of the welfare state (postponement of the reforms of pension and social systems), and closely related, high taxation and overregulation of the economy.

Its not just companies that compete with each other in the global economy, but national economies and social and economic structures as well. In spite of their deficiencies, Europe's global companies are the leading players of worldwide competition; their competitive weaknesses derive mostly from the social and economic structures of their home countries.

Europe's position in the global competition in the following decades will significantly be determined by the extent to which it will be able to execute structural reforms. While Europe is in a good position regarding the competition of industrial products (although China is a special issue), its macroeconomic performance indicators are worse than those of the United States. The USA achieved an average annual growth rate of 3-4 percents in the last decades, while the EU only grew at a 2-3 percent rate. Unemployment rate in the USA was 4-5 percents in contrast with Europe's 8-9 percents. The institutional and regulatory deficiencies principally appear in bureaucratic overregulation, overtaxation (the ratio of taxes to GDP is 30 percent in the US and 42 percent in the EU) and the delays of the reform of the welfare state. 
Hungary has become highly integrated in the world economy in the last 15 years, which increase the constraint of the reforms. The global competitiveness of the economy basically depends on the private sector, especially on transnational corporations. Major developments have been executed in infrastructure (communication), and it is favourable that significant EU funds are available for the further convergence. Their efficient spending of these resources and the improvement of our country's absorption capacity are the crucial issues.

The performance of Hungary regarding "structural reforms" has been controversial so far. The reforms of public finances as well as the budget would be especially urgent, which is closely connected to issues like health care, public administration or social policy. As a matter of fact, it should be called a complete reform of the state, which includes far more than the reform of the budget or governance. The question is more about what functions one would like the state to perform, and what functions should be left to society (civil organizations, municipalities, interest representation organizations, etc.). What we spend money on, how much do we spend on it, is it necessary to spend that much (public procurement, development programmes, subsidies for several organizations)? I assume that disciplining pubic procurement would by itself result in a perceivable improvement of the budget.

Budgets and economic policies generally have four major functions. They finance social development, they purchase and finance public goods and public services, they regulate the economy and they redistribute national income by reallocating income from the rich to the poor in name of social cohesion. The primary task would be creating markets for public goods and services. Although these are different from general goods in terms of allocation and financing, they do possess the fundamental characteristics of goods. Their production and distribution have real costs, which can be optimized by rational management; a positive return on the investment is required; supply and demand mechanisms are the same; the providers of services are also rewarded (contrary to Marxian dogmas, they create value), so management is a relevant requirement, just like in any other sectors. According to the logic of the market, we purchase these goods the same way any other good, but we pay for them indirectly with taxes. Their prices must be paid, "there is no such thing as free lunch" as it is commonly said. The source of the problems is that politics and economic policy are still mixed up in this field in most countries of the world, and governments only enforce social standards in an inconsistent way varying in form and extent. This is especially relevant to countries where the welfare state has long traditions. The welfare state should not be torn down, but be made more efficient through reforms.

Nowadays the Hungarian state budget struggles with the vicious circle of free-riding. The state undertakes public services, but it is not able to finance them 
because funds from taxes are not adequate. Public services are used by a great amount of free-riders, who fail to pay taxes. Thus the state is also free-riding on the service providers by not providing the funds, and paying low wages for the participants. It is traditionally free-riding on teachers and doctors education and public health care are free. Then, the service provider is free-riding on the consumers by providing lesser and lower quality services. One of the reasons why this phenomenon does not grow to considerable proportions is that teachers and doctors have a professional calling and most of them give their maximum despite the humiliatingly low pay. The society is conscious of all this and tries to compensate the doctors by bribing them to guarantee quality service. The hospital is free-riding on the state when it bills for services that were not even provided. The circle is full and we should break out of it as soon as possible.

Changing public management and the public service sectors needs far-reaching and long-term reforms. Such reforms affect the structure and operation of the entire economy, that is why they can only be executed cautiously, with due precautions and gradually. The reforms would require thorough professional discussions, and social and political interdependences should be considered appropriately.

There is only chance for a solution if unsolved questions are subject to debates. Western countries resolutely face the problems, and have debates even when it only seems to increase confusion. Confusion later turns into a clear picture, and the clear picture into an acceptable solution, while silence results further silence, uncertainty and failure (Ormos 2007).

A comprehensive reform strategy is needed, which seizes problems and tasks in their complexity and linkages. An action plan should be linked to this, which would schedule the reforms and, for instance, define the tasks over political terms. Reforms should be considered as public affairs and national affairs. The reforms serve for the rise of the nation, modernization, our successful performance in the globalizing world as well as our long-term welfare and future. This is not an easy way and successful examples are quite rare. Maybe I would mention Spain, where the people were made to understand that the welfare of the population requires stabilization and it is worth making a sacrifice for. The dilemma for Hungary today is that reforms are only possible in a few years distance, if equilibrium and stability are achieved, as the current situation does not make real and radical reforms immediately possible.

We know that reforms cannot be executed in a couple of days, and the full feasibility of market-based budgets is not even sure. But we should, by all means, approach to market principles and quit feudal traditions. We hear the call for everyone to take part in paying for public services day by day. This "equality of sacrifice' is a result of the democratization of late feudalism, meaning that the nobles 
should pay taxes as well. A Market-based budged has little to do with this; it only confuses matters. In a modern budget, equality of sacrifice is only meaningful if we talk about repaying debts or international liabilities, but not when we pay for services. Glossing over the facts only serves for paternalistic populism.

Despite the sort-term constraints, reforms of public education or health care can fulfil their functions only in if we understand that no funds should be taken away from these particular sectors, but investments should be made. Major investments would be required, especially in health care, because we have experienced such an immense improvement of technologies and scientific discoveries during the last decades, that health care funding built on stethoscope examinations is unable to follow them. Thus, the principle of providing high level services is becoming an illusion in international comparison. Public investments are not available, especially when budget restrictions are on the agenda. There is no option but to open health care for the investments of the private sector. The opportunity has been opened for private entrepreneurship for a long time, but investments meet difficulties in certain fields.

The aim of the reforms is to improve the level of consumption, to ensure that the vast majority are better off, to make public management more reasonable and to grant fair rewards for service providers. Actually, reforms should be organized based on a wide social agreement. Well designed reforms and action plans should be communicated to all stakeholders with persuasion. This is the only way to avoid conflicts. There will be no real support from society if the results of reforms cannot be made perceivable. Health care should only be reformed in a way where both the medical profession and the patients benefit. A knowledge-based society cannot be built and education reformed if it does not result in the fair compensation of teachers. Reforms must be sustainable; there is no point in making reforms if the political opposition makes their dismantling a priority of their programme for the next term. Moreover, reforms do not only need the understanding of the society, but a kind of social contract is required in several fields.

The success of reform is endangered by reform dogmatism and voluntarism, which is often summarized as ultra-liberalism. Unfortunately reform policies are tempted by populism as well. "Smaller state" and the promise of radical tax cuts are such populist slogans. Tax reduction is a good and desirable programme, but makes sense only in the framework of extensive reforms. Only real and well-communicated reforms can create conditions in which citizens feel responsible for themselves. The principle of "the less state intervention, the better" is only true when we also mention which functions the state should give up. We hear victorious reports on the number of people fired from certain public institutions, but we are not aware whether this is actually good, or do the staff cuts threaten the given institutions capacities to carry out their jobs. Tax reduction is a similar typical 
dogma that is enthusiastically promised by all political powers, but usually everybody forgets about the background analyses. The most inadequate situation is when responsible political figures make a statement that the worst thing to do with money is to give it to the state, because the state only wastes it. After politics itself calls upon tax evasion, only insane people pay tax. Let there be no mistake, I totally agree with the efforts to reduce state bureaucracy or taxes. However, it should be examined what expenses are cut and whether this damages the society or the economy. Of course, on the first level, entrepreneurs would say that paying no taxes at all makes them the most competitive. But this way they tacitly assume that public services will still be available to them. Their competitiveness would be in great trouble if it turned out that there is nothing to free ride on. Competitiveness is decreased by taxes as additional expenses, but it is increased by the availability and rational use of public services. Flat rate tax system is a similar myth. There are serious professional debates taking place and opinions are divided. A flat tax system might be successful in special circumstances, but it is essential to make clear whether those circumstances actually exist.

The social aspects of the reforms must be managed. The separation of social policy (who has to finance the reforms, to what extent and for whom does the state provide free services) from economic policy is impermissible. If left alone, citizens must be able to care for themselves. The efficiency of the current social policy and social security is low; they are also dysfunctional, unsustainable, wasteful, and unfair. The comprehensive and fundamental reform of the entire social system is an essential element. The key to success is to find a compromise between efficiency and social fairness; market principles and efficient social regulation; global competitiveness and welfare policies.

\subsection{Knowledge-based economy and the reform of education}

There are several different approaches to the interpretation and definition of knowledge-based society, and there is no mutual understanding. The most important momentum is that knowledge has become the key factor of production during recent decades. Three factors are differentiated in industrialized societies: land, capital and labour. The main dilemma for the economists was the efficient allocation of these "scarce resources", which led to the theory of the "limits of growth" in the late 1970's (Meadows 1972). "The situation is different if we talk about knowledge. Information and knowledge are new factors of production. They are unlimited, renewable, infinitely interchangeable and recyclable resources." (Kahane 2006) More precisely formulated: "Today, the leading resource, the absolute key factor of production is neither capital, nor land, nor labour. It is knowl- 
edge" (Drucker 1994). Drucker implemented the ideas of "knowledge work" and "knowledge worker" in the 1960's. According to him, the most significant sources of value creation are productivity and innovation. Of course, emphasizing knowledge does not eliminate the scarcity of the traditional factors of production.

Technological development has become the main factor of economic growth, and $R \& D$ expenses are of the highest importance. This process is indicated by the increasing share of R\&D expenses among production costs, as well as the domination of high-tech industries in the economy. The rising significance of knowledge is also expressed by the investments in information and communication technologies and education, the diffusion of ICTs and the internet. These expenses can be the essential to improving cost efficiency. Economic convergence is not possible without the development of education, R\&D and without "bridging the digital gap".

In knowledge-based societies, the relationship between the revolution of technology and science does not only lead to the development of new technologies, but also has effects on social sciences, for example on management and marketing sciences, corporate governance and even public administration and public management. The social and economic processes have become so complex, especially in the recent decades, that they require thorough academic level analysis by using methods known only by highly qualified professionals. Not only does the governance of companies have scientific backgrounds today, but it is also clear that in case of public management voluntarism of politics can cause serious harms to a country, thus it would be practical to leave decisions of greater importance to independent professionals. The independence of the central bank or the founding of budgetary councils can be regarded as the first, maybe uncertain, steps in this direction

Education is one of the most important strategic sectors of the economy in a knowledge-based society. Knowledge becomes a public property; specifically, education must make knowledge a public property. Education becomes universal on all levels, nowadays even on the level of higher education. This process is influenced by demographic factors as well. The average life expectancy has already significantly risen during the last decades, but if the results of the current biological-genetic revolution turn to be general, the average age of 100 years can be typical in just 50 years. In biological terms, it is possible. The time spent in work has been around 40 years, but it can increase similarly to the period of education. The concept of lifelong learning can partly answer the challenges; however, the fundamental reform of the pension system is inevitable.

One of the most important questions in respect of the knowledge-based society is about the knowledge that should be transmitted to students. Nowadays it is often heard that higher education must be drawn nearer to the "market". This of 
course has some relevance if we talk about the ratios of students studying various disciplines, which unfortunately follow the demand and interest of students instead of the requirements of the labour market, resulting in an oversupply of economists and lawyers and a lack of engineers and scientists. The competition for public and private funds led to irresponsible policies by higher education institutions. It was not in their interest to tell the students that by increasing their numbers in "trendy" professions, their future unemployment outlooks deteriorated.

Teaching knowledge and skills that are useful on the labour market is only one of education's main tasks. Of course, it is important for the students to get to know reality and not to live in an ivory tower. Much more practical knowledge is needed in numerous fields. But still, the university should not provide knowledge for the workplace but after teaching the basic professional knowledge, it should train professional intellectuals with logical minds and an ability to solve the problems of their specialization. Universitas means that all main factual material and methodology of the specific science must be taught. Thus, the ability to think like an economist or a lawyer must be taught as well. As Loránd Eötvös wrote in 1887, this demands high professional requirements:

It does not make a good judge or lawyer if someone can immediately cite articles from a law regarding the court case presented and it does not make a good doctor if someone throws a glance at the patient and decides at once which medical treatment to apply. Disorders arising in respect of our financial circumstances or even our organisms are usually so complex that it is absurd to think of their healing on the basis of any predetermined formulas or receipts. The assessment of such cases requires the independence in thinking, which cannot be provided by practical rules but by the expertise in the fields of the science that resulted those practical rules. Thus, if we expect the university to educate useful people for the country, we have to preserve the scientific characteristics of university education carefully (Eötvös 1985).

"Civilized" people must be trained instead of meeting the restricted demands of the labour market. Knowledge-based society requires that an increasing number of people capable of independent thinking should be trained. It is especially relevant in the case of higher education: it should train logical minds, problem-solving, innovative professional intellectuals, who are able to improvise and have intuitions.

Education should also adapt to the third wave, which is a slow and painful process. Post-industrial societies need people not only with high intelligence quotients, but such additional characteristics as imagination, motivation, courage, energy, entrepreneurial attitude, emotional intelligence, communication skills, innovation skills, adaptability to changing circumstances, as well as common wisdom (Kahane 2006).

The reform of the education started in recent years in Hungary, but we are still far away from the execution of the tasks of great importance, even from the determination of the main directions or the substantial requirements. Primarily, the 
substantial and methodological issues of education development require an analysis in connection with the knowledge-based economy. Education has cultural, training, and socialization (pedagogical) functions. We are not really aware of what factual materials education should transmit in the age of the internet, how the characteristic and structure of education and training can be transformed through information and communication technologies, what lifelong learning means, what school system it requires and how the entire knowledge-based society built. Are multifunctional educations centres needed, which are able to adapt to the demands of lifelong learning, or is it sufficient to improve the structure of the current school system? The work is not an easy one, as the education system of the last 200 years must be changed radically.

The issue of equal opportunities is a regular question regarding the reform of education. It is no doubt that reaching or at least approaching equal legal and social opportunities is a great achievement that must be protected. However, individuals are not equal due to their unique biologic characteristics, and believing that they can be made equal is an illusion. It is especially important in the age of the knowledge-based society, when we can and should take on the differences, and education must be constructed based on the demands of this variation in abilities.

According to Jeffrey Sachs, only 15 percent of the world's population is able to innovate, half of it to adapt, and one third is unable to both innovate and adapt. It is a debatable point, but a real dilemma. We might assume that it is no problem when productivity is high, as a significant part of the society can become provided for. But this is unacceptable; everybody has an ability or skill that must be developed.

Thus another definition of equality is needed instead of what we propagate today under equal opportunities. In the age of the knowledge-based society a truly fundamental question of education is how the equality and diversity can be created. Ones who argue that providing similar education for the outstandingly gifted, the average and the modestly talented students makes the institutional system of education democratic are wrong. I would say that instead of equal opportunities, the creation of opportunities and individual talent support should be emphasized in education. Talent support should be started already in kindergarten and it obviously requires different methods on different levels of education. Talents could be discovered and taken care of by appropriate professionals later through small group trainings for example. Of course it is much more costly and requires more efforts than currently, but this is the requirement of the knowledge-based society. As an economist, I could say that our present educational system is the wasteful "production" human resources, which is intolerable in a knowledge-based society. While a new education system would cost more, its economic and social benefits would also multiply. 
Of course no racial, religious or cultural discrimination is allowed in schools. All kinds of segregation must be rejected. If children vary in their abilities when transmitting knowledge, it does not mean that these children of different talents cannot be in the same class when the school executes its function of socialization.

Results will stay limited until reforms only deal with how money could be saved from the system in order to decrease the budget deficit. In higher education, the shift to a multi-level system, international compatibility and the emphasis on quality assurance were major steps. However, the reforms of the recent years were not able to change the insufficient funding of the system, which caused serious negative consequences regarding quality standards. Due to the "Bologna-process", higher education has become more open and flexible, it has opened for European mobility and the compatibility of universities and specializations has been created as well. But we still need further reforms, which are in harmony with the requirements of the knowledge-based society as well as the possibilities of the information society.

The question arises: can Hungary be considered a reform country? We were that for a long time. We became a reform country after 1968, and these reforms were of crucial importance in respect to the transformation following the 1980's. The reform of taxation and the banking system (1986-1988) as well as the privatization and bankruptcy laws (1988-1995) should be pointed out. The latter might be considered as a special structural "shock therapy" as it played a major role in the rapid and radical structural transformation of the Hungarian economy. The reform of the pension system (the introduction of private pension funds) as well as several steps towards the reform of the health care system should be emphasized particularly. But the reform wave of recent years is now over, even though the only way of stabilizing our economy and retrieving our lost honour is through further structural reforms.

\section{EXTERNAL RELATION MODELS OF THE EU}

The EU might become an organization with 35-38 members in the next decades. This will result in the significant growth of internal diversity (in economic, cultural, social and civilizational sense). A further large-scale expansion is however not due in the short run. The consolidation of the EU after the recent expansions (27 member states and the future accession of Croatia) may require 20-25 years, while maintaining the processes of internal cohesion and external convergence is important. Further expansions will take a longer time to happen.

There is a region of countries bordering the Union especially from the east and the south, with whom we have strategically important external relations. It is our 
interest to make this region secure and prosperous, an integration zone that is more closely connected with us than other any other countries. (Not including West-Balkan as it is geographically "indoors".) A part of these (substantially Turkey) already has accession negotiations; another part intends to join, but their accession is not on the agenda (the Ukraine or Georgia); while the third group does not even want to join the EU (Russia, Mediterranean countries), but we are interested in a close integration with them as well.

The current accession forms are not sufficient even for those who intend to join, or the others. Currently, the EU can offer either associate partnership or full membership, but there are no transitional forms between them. Originally the European Economic Area was meant to be one, but it turned out that it is no more than an improved partnership and the vast majority of EFTA countries chose full membership instead of it. The European Agreements were formulated within wide bounds based on the similar objective, but Hungary and the other CEE countries also realized that its interests were broader.

The advantages of full membership are far-reaching:

- further opportunities of trade and economic integration;

- better possibilities for modernization and convergence;

- joining the common policies;

- the principle of cohesion applies only to members;

- increased security;

- stronger guarantee of democracy;

- full participation in institutions and decisions;

Thus, the issue of temporary solutions arises (associate membership, partial membership, etc.), in which respect some provisions were made on the level of political declarations, but it was not studied in detail. These provisions include:

- improvement of security by involving neighbours in the cooperation in justice and home affairs;

- improvement and further development of the New Neighbourhood Policy;

- improvement of the European Economic Area (Norwegian model);

- involvement in common policies;

- partial extension of cohesion and solidarity to non-members;

- "Associated State" - a limited participation in institutions and decision-making.

The participation in common policies can be of fundamental interest to certain countries, if for some reason they do not want to reach full membership, or the EU 
does not want them to become full members. (For example: can Euro-zone membership be possible without full EU membership, as it come up in the case of Iceland?) Participation in common institutions should not be ruled out either, which has precedents in several federative countries. Involving counties in making decisions that affect them can be especially important, even if it means only involves their hearing and participation in the discussions and does not provide rights for vetoing these decisions. The increase of financial transfers could be an element of such a special status, even if it is a difficult issue with the current financial and budget problems. These transfers would serve the interests of the Union directly (development of infrastructure for example).

The most dangerous issue in the current circumstances is the case of Turkey, where the postponement of accession might result in extremely serious and unwanted consequences (security threats or a halt in the promising Europeanization process of Turkey). Although Hungary has an interest in the Turkish accession, it is a fact that the Union is currently not able to integrate (absorb) Turkey. Thus, it would be desirable to find transitional solutions, which, in this particular case only postpone but do not substitute full membership. A similar solution should be found for the integration of such countries as the Ukraine.

\section{THREE SHORT COMMENTS}

1. I agree with Csaba Csáki that the CAP needs fundamental and radical reform. Not abolishment, but structural transformation is required. Its preservation is especially important for the new member states (Hungary for example) because the agriculture of these countries is still lagging behind.

It would be reasonable to gradually replace price and income subsidies by development subsidies and to ensure their most efficient utilization. When mentioning development subsidies, I do not in the least think of financial transfers only, but professional consultation; knowledge, technology and innovation transfer; market research and reasonable protection against unforeseeable and unavoidable market impacts.

The liberalization of agribusiness is inevitable in the long run; more open global agro-markets are becoming typical. Thus, global competitiveness should be the focus of development policy.

The CAP has significant social and environmental functions. Rural development and handling the problems of farmers are of strategic importance in the future too.

In the age of chemical, biological or nuclear weapons, the safety of food-supply is provided by the globally open markets instead of autarky (as it used to be). 
2. It is widely agreed that the common budget of the EU does not meet the requirements it should and is dysfunctional. The integration of the economies of EU member states has reached an exceedingly high level in the recent decades. With the accession of 12 new countries, the EU undertook further great integration tasks. Neither in size, nor in structure, nor in functions is the budget of the EU in harmony with these tasks

Budgets usually have four important basic functions: development, service provision, regulation and cohesion (compensation). The budget of the EU executes these functions in a very limited and incomplete way. For instance, its service providing function is minimal, while it is unwilling to acknowledge its compensation functions. Although large regional or social disparities destabilizing the economy and hindering the optimal allocation and efficient utilization of resources cannot be solved by structural funds alone, they are required because deeper integration (such as the single market or currency) can make these problems even more pressing.. Advantages and disadvantages are not distributed evenly, which requires corrections. In fact, the integration process has been a positive sum game for all participants yet, but it does not set the inequalities aside. Even the partnership status proved that we undoubtedly profited from the integration, but the earlier members had won much more. The fact that our smaller benefits were more important to us than the greater gains for the economies of the earlier counties does not change the problem. Moreover, while the business sector is the major winner, the budget has to compensate the losers, which is mostly financed by the consumer (the voters). Of course I could only present a brief and simplified description of the problem.

What roles should the EU budget play? A wide literature discusses this issue and I will not go into details. However, I would like to mention a particular question. The development functions of the EU budget are obviously in close connection with the progress of the integration. From a sub-regional viewpoint (that is to say within the Central European region) we have special and strong strategic interests in it. Cross-border cooperation is one aspect of this, but it also means the rebuilding of a historically traditional integration as well. It would be necessary to determine or national interests accurately and firmly in this issue. However, such development of the infrastructure is at the same time the interest of the community as well.

It is a bit tougher question how the execution of these functions should be financed, as this touches the political context. Such critical problem is the issue of "own revenues". The reforms of the recent years were setbacks in this field, as the EU moved towards a "membership fee" proportionate to the GDP. Raising the idea of an EU tax and tax authority is not popular; all political powers regard it as political suicide. In fact, without a general tax reduction, it has no relevance. But if 
income taxes are reduced, nobody really cares if besides the local and the national levels the union level also joins. It would be ideal to precisely identify the public services provided by the common budget and to finance them mostly from the money of their beneficiaries. In such respect, national budgets are not transparent either, as frequently it is not the beneficiaries who finance various policies. As citizens, entrepreneurs, consumers or a part of the public benefit from such services, expenses should be met by them as well.

With its 1 percent share of GDP, the budget of the EU is marginal, especially compared to its functions (especially to its potential functions). The MacDougall Report (1977) defines three stages of the federal budgets:

- Pre-federal budget with expenses between 2-2.5 percents of the GDP.

- Federation with small public sector and expenses around 5-7 percents of the GDP.

- Union operating with large public expenses that reach 20-25 percents of the total GDP.

The current dimensions are not in line with the level and the requirements of the economic integration of the Union.

3. Hungary has several interests in joining the Euro-zone as soon as possible. Membership requires serious sacrifices, but the balance of advantages and disadvantages is definitely positive. Besides the increasing "euroization" (which translates to growing indebtedness), the most significant threat now is the extraordinary growth of exchange rate risk. This is a time bomb for consumers, entrepreneurs and for the state, and its solution is only possible by escaping forward (joining the Euro-zone).

I must emphasize that the several elements of the structure of the EMU and the requirements set for the entrants (Maastricht criteria) are disputable, and do not suit our circumstances and interests. The relevance of the inflation targets $(2$ percent cap and its rigorous specification) and the related policy of thr ECB are also questionable. As The Economist remarks: "Inflation targeting is the new gold standard, largely guiding even the conduct of the European Central Bank, which retains a "monetary pillar" (The Economist, 9 June 2007: 86). The trouble is that the problems return from the 1920's and the 1930's, when the European countries contributed to the development and the deepening of the great depression by holding onto the preservation of the gold standard tenaciously for the sake of financial stability. The dilemma of dynamic growth and financial stability seems to remain irresolvable in connection with the structural symptoms of the crisis. The other 
side of the coin is that the dynamic development of the economy is not taken into consideration by mechanically applying the inflation targets (Maastricht criteria for instance); the 2 percent cap is different in case of a two digit improvement in productivity (equilibrium inflation) and in case of a stagnating economy. It is nonsense to require an emerging country to deflate its economy without a reason, for the sake of Euro-zone membership. I would like to stress that I have not the slightest intention of questioning the necessity of strict fiscal and monetary policies aimed at growth without inflation.

The inflexible application of fiscal objectives is also a related issue. On the one hand, the 3 percent budget deficit cap can also have deflation effects to an undesirable extent. On the other hand, it does not consider the performance of the economies. The model of the 3 percent budget deficit cap was based on 2.5-3 percent annual growth. The situation is quite different when economic growth is double or triple. The structure of the budget is an additional question. Seven percent of the expenses of the Hungarian budget are debt service. Thus, the surplus of the primary budget already deflates the economy, forcing it to restrictions instead of desirably allowing it to outgrow its debt.

On the other hand, I do not think it is justified to fret about the growth sacrifices that monetary integration requires. In such a globally open economy like Hungary, economic growth basically depends on global competitiveness. However, any steps that serve for this competitiveness can be successful only in harmony with financial stability, especially if we aim to sustain economic growth in the long run. The situation of social "sacrifices" is similar. Our current welfare policies are dysfunctional, prodigal, illogical, socially unfair and have a long list of further problems. Their reform is unavoidable regardless of our Euro-zone membership. The sooner we are over it, the better.

\section{NOTES}

1 "Other terms to be found in the acquis academic as means of conceptualizing the political and/or constitutional physiognomy of the Union include: proto-federation, confederance, concordance system, network governance, quasi-state, Staatenverbund, meta-state, market polity, managed Gesellschaft, nascent Gemeinschaft, regional regime, federated republic, sympolity, confederal consociation, and so on" (Chryssochoou 2001: 23).

2 The Economist, 6 November 2004, Commentary to the Wim Kok Report.

\section{REFERENCES}

Balcerowicz, L. (1995): Socialism, Capitalism, Transformation. Budapest: CEU. Chryssochoou, D. N. (2001): Theorizing European Integration. London: SAGE Publications. 
Drucker, P. F. (1994): Post-Capitalist Society. New York: Harper Business.

Eötvös, L. (1985): Az egyetem feladatairól [On the Roles of the University]. Budapest: Magvetö Kiadó.

Giddens, A. (1996): “Globalization: A Keynote Address”. UNRISD News, No. 15.

Kahane, Y. (2006): "Technological Changes, the Reversal of Age Pyramids and the Future of Retirement Systems". European Papers on the New Welfare No. 4.

MacDougall Report (1977): Report of the Study Group on the Role of Public Finance in European Integration. Brussels: Commission of the European Communities.

Meadows, D. et al. (1972): Limits of Growth. London: Earth Island.

Ormos, M. (2007): "Politikaelméleti viták a nyugati világban [Debates in Western Political Theory]. Élet és Irodalom 20 April 2007.

Sachs, J. (2000): “Sachs on Globalisation". The Economist 14 June 2000. 